\title{
Effect of waste milk pasteurization on fecal shedding of Salmonella in preweaned calves
}

\author{
Tom S. Edrington, ${ }^{* 1}$ J. Armando Garcia Buitrago,† G. Robert Hagevoort, $†$ G. H. Loneragan, $\ddagger$ \\ D. M. Bricta-Harhay, $\S$ Todd R. Callaway, ${ }^{*}$ Robin C. Anderson, ${ }^{*}$ and David J. Nisbet ${ }^{*}$ \\ *Food and Feed Safety Research Unit, Southern Plains Agricultural Research Center, USDA-Agricultural Research Service, \\ College Station, TX 77845 \\ †Agricultural Science Center at Clovis, New Mexico State University, Clovis 88101 \\ †International Center for Food Industry Excellence, Department of Animal and Food Sciences, PO Box 42141, Texas Tech University, \\ Lubbock 79409 \\ §USDA, Agricultural Research Service, Roman L. Hruska US Meat Animal Research Center, Clay Center, NE 68933
}

\begin{abstract}
The objective of the current research was to determine if pasteurization of nonsaleable waste milk influences fecal Salmonella concentrations and prevalence, or antimicrobial susceptibility and serotype of the cultured isolates. Holstein dairy calves $(\mathrm{n}=211)$ were housed on a single commercial dairy in the southwestern United States and randomly allotted to be fed either pasteurized (PWM; $\mathrm{n}=128$ calves) or nonpasteurized waste milk (NPWM; $\mathrm{n}=83$ calves). Fecal samples were collected via rectal palpation or from freshly voided, undisturbed fecal pats, weekly during the first 4 wk of the animal's life and then again at weaning. Eight total collections were made and 1,117 fecal samples cultured for Salmonella. One isolate from each culture-positive fecal sample was preserved for antimicrobial susceptibility screening and serotyping. Sixty-nine percent of the fecal samples were culture positive for Salmonella with no difference due to treatment (67.7 and 69\% Salmonella positive for PWM and NPWM treatments, respectively). Few fecal samples $(178 / 1,117 ; 15.9 \%)$ contained Salmonella concentrations above the limit of detection ( $\sim 1 \mathrm{cfu} / \mathrm{g}$ of feces) with concentrations ranging from 1.0 to $6.46 \mathrm{cfu}\left(\log _{10}\right) / \mathrm{g}$ of feces. Concentration was not affected by treatment. Seventeen different serotypes were identified, the majority of which were Montevideo and Anatum. A greater percentage of Typhimurium (87 vs. $13 \%$ ), Muenchen (88 vs. $12 \%$ ), and Derby (91 vs. $9 \%$ ) were recovered from calves fed PWM compared with NPWM-fed calves. Conversely, Newport (12.5 vs. $86 \%$ ), Bredeney (22.2 vs. $77.8 \%$ ), and Muenster (12.5 vs. 87.5\%) were lower in PWM compared with NPWM
\end{abstract}

Received February 28, 2018.

Accepted May 3, 2018.

${ }^{1}$ Corresponding author: tedrington@diamondv.com treatments. The majority $(66.7 \%)$ of isolates were susceptible to all of the antibiotics examined. Results from this one commercial dairy suggest that milkborne Salmonella is not an important vector of transmission in dairy neonates, nor does pasteurization of waste milk influence fecal shedding of this pathogen. Caution should be used, however, when extrapolating results to other farms as Salmonella contamination of milk on farm is well documented. The potential benefits of pasteurization in disease prevention outweigh the potential risks of feeding a nonpasteurized product and warrants incorporation into any calf-rearing program using nonsaleable waste milk for feeding young dairy neonates.

Key words: Salmonella, waste milk, pasteurization, calf

\section{INTRODUCTION}

Dairy producers use a variety of liquid feeds for their young calves including milk replacers, whole milk, and waste milk. Waste, or discard milk, is milk from cows treated with antibiotics for mastitis or other illnesses and cannot be sold for human consumption (Chardavoyne et al., 1979). A survey conducted in 2002 reported that $87.2 \%$ of dairy farms in the United States use waste milk to feed their calves (USDA National Agricultural Statistics Service, 2002). Several studies have reported that the incidence of scours and growth rates in calves fed waste milk are comparable to those fed whole milk (Chardavoyne et al., 1979; Keys et al., 1980; Kesler, 1981). This practice is not without its dangers, however, as feeding waste milk can expose young calves to diarrhea-causing pathogens and disease. Escherichia coli, Salmonella, Streptococcus, and Staphylococcus are bacteria that have been identified in waste milk (Selim and Cullor, 1997). In an effort to eliminate or reduce the transmission risk, many producers are incorporating pasteurization of the waste milk in 
their calf management program. Pasteurization, if done correctly, has been shown to kill important bacteria such as Mycobacterium paratuberculosis (responsible for Johne's disease), Salmonella, and Mycoplasma (Butler et al., 2000; Stabel et al., 2004). Additional benefits of on-farm pasteurization include reduced diarrhea and pneumonia and improved weight gains (Jamaluddin et al., 1996). Although bacterial counts can be significantly reduced by pasteurization, milk handling after pasteurization can increase bacterial contamination substantially to levels similar to those prepasteurization (Elizondo-Salazar et al., 2010).

Salmonella is commonly isolated from mature dairy cattle where it typically thrives in the gastrointestinal tract (GIT) as part of the commensal bacterial population without causing any harm to the animal (Fitzgerald et al., 2003; Edrington et al., 2004, 2008a; Loneragan et al., 2012). In preruminant (1-2 wk of age) dairy calves, however, Salmonella is a serious bacterial pathogen and a significant causative agent of neonatal calf scours (Moore et al., 1962; Rings, 1985). Numerous Salmonella serotypes have been isolated from young dairy calves, although those associated with increased virulence and multidrug resistance are often cultured (Edrington et al., 2008a). Due to the sensitivity of neonatal calves to Salmonella and the propensity for the more virulent strains to thrive in these young hosts, methods such as waste-milk pasteurization have been employed to combat this pathogen. Even so, published reports examining the effect of waste milk pasteurization specifically on Salmonella in dairy calves are scarce. Previously, we examined the colonic microflora (via pyrosequencing) of dairy calves from 1 wk to 6 mo of age (Edrington et al., 2012) fed either pasteurized (PWM) or nonpasteurized waste milk (NPWM). Salmonella was consistently detected in the younger animals fed NPWM, whereas total bacterial diversity was greater for those animals fed pasteurized milk. However, the study compared animals on 2 different farms, and although location, housing, and general management were the same or very similar, subtle differences could have affected these results. Indeed, differences in Salmonella prevalence have been reported for dairies located within the same region and managed similarly (Edrington et al., 2004, 2008a). Therefore, the current study was conducted to determine the effect of wastemilk pasteurization on fecal shedding of Salmonella, the distribution of Salmonella serotypes, and antimicrobial resistance of cultured Salmonella isolates in dairy calves on a single commercial dairy farm in the southwestern United States.

Tetracycline and $\beta$-lactam residues, 2 antibiotics used most commonly in lactating dairy cows (Sundlof et al., 1995), were detected in $63 \%$ of waste milk and milk- based fluids (Selim and Cullor, 1997). The $\beta$-lactam residues were more often associated with dairies utilizing waste milk, whereas the tetracycline residues were mostly associated with farms using milk replacers (Selim and Cullor, 1997). In recent years there has been considerable controversy over the inclusion of antibiotics in rations of farm animals because of the possible emergence of antibiotic resistant bacteria (Salisbury et al., 2002). Wray et al. (1990) reported no differences in the prevalence of antibiotic-resistant Escherichia coli in the feces of calves fed milk from antibiotic-treated cows versus those fed a milk replacer. Resistance to penicillin and ampicillin was reported in Escherichia coli cultured from calves fed waste milk; however, the authors' presentation of the data makes it difficult to determine how this differed from those fed milk replacer (Selim and Cullor, 1997). As previous research has reported antibiotic residues in waste milk and the potential exists for this to influence antimicrobial susceptibility of the microbial fauna of the calf, our second objective was to examine the antimicrobial susceptibility profiles of the cultured Salmonella isolates.

\section{MATERIALS AND METHODS}

\section{Animals and Sample Collection}

Holstein dairy calves were housed on a single commercial dairy in the southwestern United States throughout the sample collection period. Calves were either born on the dairy or born on other dairies and transported to this dairy at 1 or $2 \mathrm{~d}$ of age. Calves were housed in commercially available polyethylene hutches affixed with a $1 \times 2 \mathrm{~m}$ outdoor pen made of welded wire panels. Soon after birth or at arrival to the farm, calves were randomly allotted to be fed either PWM ( $\mathrm{n}=128$ calves) or NPWM ( $\mathrm{n}=83$ calves). For convenience of the farm personnel, calves in each treatment were housed in separate rows. Animals were fed waste milk twice daily, approximately $2.0 \mathrm{~L}$ per feeding, until they would drink from a bucket (typically 1-3 d), after which they were provided $7.5 \mathrm{~L}$ of waste milk twice daily until weaning at approximately 2 mo of age. Batches of waste milk were split and pasteurized (flash pasteurization: $72^{\circ} \mathrm{C}, 15 \mathrm{~s}$ ) or not pasteurized. In addition, calves received approximately $7.5 \mathrm{~L}$ water daily and were gradually introduced to solid feeds between 10 and $14 \mathrm{~d}$ of age. Calves were generally placed alternately in rows (treatments), and other than the type of waste milk fed, were all managed the same as per typical calf-rearing protocols for this region of the United States. Due to concerns with feeding NPWM, more calves were placed in the PWM treatment per the dairy owner's instructions. 
Fecal samples $(10-20 \mathrm{~g})$ were collected via rectal palpation or from freshly voided, undisturbed fecal pats, weekly during the first $4 \mathrm{wk}$ of the animal's life and then again at weaning. Samples were collected into sterile palpation sleeves, placed on ice and shipped overnight to our laboratory in College Station, Texas, for bacterial culture the following day. Eight total collections were made and 1,117 fecal samples cultured for determination of Salmonella concentration and prevalence as described below. Waste milk (PWM and NPWM) samples were collected before feeding at each weekly fecal collection and likewise shipped to College Station for bacterial culture as described below.

\section{Bacterial Culture}

Ten grams of each fecal sample was mixed with $90 \mathrm{~mL}$ of tetrathionate broth, $1 \mathrm{~mL}$ of this mixture removed, and $50 \mu \mathrm{L}$ direct plated on xylose lysine deoxycholate agar [Oxoid, Basingstoke, Hampshire, UK; supplemented with novobiocin and nalidixic acid (25 and 20 $\mu \mathrm{g} / \mathrm{mL}$, respectively)] using a commercially available spiral plater (Spiral Biotech Autoplate 4000, Advanced Instruments Inc., Norwood, MA). Plates were incubated overnight $\left(37^{\circ} \mathrm{C}\right)$ and black colonies counted and converted to $\mathrm{cfu}\left(\log _{10}\right) / \mathrm{g}$ of feces. The tetrathionate/ feces mixture was incubated overnight at $37^{\circ} \mathrm{C}$ before a sub-sample $(100 \mu \mathrm{L})$ being transferred to $5 \mathrm{~mL}$ of Rappaport-Vassiliadis broth (Remel Products, Lenexa, $\mathrm{KS}$ ) and incubated at $42^{\circ} \mathrm{C}$ for $24 \mathrm{~h}$. The RappaportVassiliadis enrichment was plated on brilliant green agar (Oxoid) supplemented with novobiocin and nalidixic acid ( 25 and $20 \mu \mathrm{g} / \mathrm{mL}$, respectively) and plates incubated $\left(37^{\circ} \mathrm{C}\right.$, overnight). Presumptive Salmonella isolates were confirmed biochemically using lysine and triple sugar iron agars. One isolate from each positive sample was stored $\left(-80^{\circ} \mathrm{C}\right)$ using CryoCare bacterial preservers (Key Scientific Products, Round Rock, TX) for antimicrobial susceptibility testing and serotyping as described below.

Milk samples were cultured for Salmonella, Escherichia coli, and fecal coliforms. For Salmonella culture, $2 \mathrm{~mL}$ of waste milk was mixed with $20 \mathrm{~mL}$ of tetrathionate broth, then processed as above for the fecal samples. Escherichia coli and coliforms were cultured by mixing $1 \mathrm{~mL}$ of waste milk with $9 \mathrm{~mL}$ of tryptic soy broth, spiral plating as above onto Chromagar ECC (DRG International, Mountain Side, NJ), and incubated overnight $\left(37^{\circ} \mathrm{C}\right)$. Blue $(E$. coli) and red (fecal coliforms) colonies were counted and converted to cfu $\left(\log _{10}\right) / \mathrm{mL}$ of milk. Two to 4 isolates of each colony color were picked from each sample, if available, re-streaked on Chromagar ECC, incubated, and then frozen for antimicrobial susceptibility testing.

\section{Antimicrobial Susceptibility Testing of Fecal Salmonella and Waste Milk Isolates}

Salmonella isolates (fecal and waste milk) were screened for antimicrobial susceptibility using a broth micro-dilution method and the National Antimicrobial Resistance Monitoring System gram-negative panel for antimicrobial agents (Sensititer, TREK Diagnostic Systems, Cleveland, OH). Clinical and Laboratory Standards Institute guidelines were used for interpretation of MIC values when available (CLSI, 2010), otherwise the National Antimicrobial Resistance Monitoring System breakpoints were used (FDA, 2011). Escherichia coli ATCC 25922 was used as a quality control organism.

Serotyping of Salmonella Isolates. All confirmed Salmonella isolates were serogrouped using Wellcolex Color Salmonella tests (Remel), according to the manufacturer's recommendations. Salmonella were further serotyped using antisera for the identification of somatic and flagellar antigens (Remel). Slide agglutination was used to confirm or refine the results of the Wellcolex Color test O-group results, and tube agglutination was used to identify flagellar $\mathrm{H}$-antigens, as previously described (Andrews and Hammack, 2008).

Statistics. Binary response variables for prevalence $(0,1)$ were created. Logistic regression models were created using commercially available software (SAS System for Windows 9.2, SAS Institute Inc., Cary, NC). Exposure (calves fed NPWM or PWM) was included as the explanatory variable, whereas the binary prevalence variable was the response variable using a binomial distribution and a logit link function. Origin was included as a random intercept variable. To account for within calf clustering resulting from repeated sampling, a random term was forced into the model at the residual level with a first-order autoregressive covariance matrix. Models were repeated for prevalence of the primary serotypes recovered. Similar general linear mixed models were established for bacterial concentration. For reporting purposes, crude and model-adjusted estimates (and 95\% CI where appropriate) are reported.

\section{RESULTS}

Two hundred eleven calves, representing 4 farms of origin (birthplace), were enrolled into the study (Table 1 ). Sixty-one percent of the calves were assigned to the PWM treatment and the remaining $39 \%$ to the NPWM treatment. Of the 211 calves enrolled in the study, 170 were additionally sampled immediately after weaning. A total of 1,117 fecal samples were cultured for Salmonella, 42 and $58 \%$ of which were from calves in the PWM and NPWM treatments, respectively. Sixty-nine percent of the fecal samples were culture positive for 
Table 1. Descriptive statistics of sample numbers from experiment evaluating the feeding of pasteurized and nonpasteurized waste milk to dairy calves on fecal Salmonella

\begin{tabular}{lrc}
\hline Item & No. & $\%$ \\
\hline No. of calves enrolled in study & 211 & 100 \\
Nonpasteurized & 83 & 39.3 \\
Pasteurized & 128 & 60.7 \\
No. of calves sampled at weaning & 170 & 100 \\
Nonpasteurized & 95 & 55.9 \\
Pasteurized & 75 & 44.1 \\
Total fecal samples cultured & 1,117 & 100 \\
Total fecal samples cultured by treatment & 471 & 42.2 \\
Nonpasteurized & 646 & 57.8 \\
Pasteurized & & \\
Total fecal samples by farm of origin & 214 & 19.2 \\
A & 263 & 23.6 \\
B & 407 & 36.4 \\
C & 233 & 20.8 \\
D Total Salmonella-positive fecal samples (qualitative culture) & 765 & 68.5 \\
Fecal Salmonella-positive samples (qualitative) by treatment & 319 & 67.7 \\
Nonpasteurized & 446 & 69 \\
Pasteurized & & \\
\hline
\end{tabular}

Salmonella with no difference $(P>0.10)$ due to treatment (69 and 67.7\% Salmonella positive for PWM and NPWM treatments, respectively; Table 1).

Few fecal samples $(178 / 1,117 ; 15.9 \%)$ contained Salmonella concentrations above the limit of detection (LOD; $\sim 1 \mathrm{cfu} / \mathrm{g}$ of feces) via direct plating with concentrations ranging from 1.0 to $6.46 \mathrm{cfu}\left(\log _{10}\right) / \mathrm{g}$ of feces (data not shown). In the first collection, farm origin did not influence fecal Salmonella concentrations nor was an origin $\times$ treatment interaction $(P>0.10)$ detected; however, a treatment effect $(P<0.05)$ was observed with lower concentrations in the calves fed PWM compared with those fed NPWM [2.9 vs. 1.9 cfu $\left(\log _{10}\right) / \mathrm{g}$ of feces, respectively]. For the subsequent 6 collections, there was an effect of collection and a collection $\times$ treatment interaction $(P<0.01)$ observed, but no effect of treatment $(P>0.10)$ on fecal Salmonella concentrations (data not shown). In general, the number of animals with concentrations above the LOD declined over the course of the experimental period. There were no treatment or origin effects, nor was there a treatment $\times$ origin interaction $(P>0.10)$, observed for Salmonella concentration in fecal samples collected at weaning. Salmonella concentrations are presented in Figure 1, by collection, including data from both the first and last (weaning) collections. Actual concentrations (only animals with concentrations above the LOD) as well as adjusted concentrations [includes animals that were culture negative via direct plating but culture positive following enrichment and assigned a concentration of $1.0 \mathrm{cfu}\left(\log _{10}\right) / \mathrm{g}$ of feces] are presented. Overall concentrations were relatively consistent throughout the experimental period, the exception being collections 5 (PWM treatment) and 8 (NPWM treatment) where a few animals had higher Salmonella concentrations compared with the other collections. Across collections, Salmonella concentrations averaged 3.2 and 3.1 (animals culture positive via direct plating only) or 1.4 and $1.5 \mathrm{cfu}\left(\log _{10}\right) / \mathrm{g}$ of feces [animals culture positive following enrichment but below LOD via direct plating and assigned concentration of $1.0 \mathrm{cfu}$ $\left(\log _{10}\right) / \mathrm{g}$ of feces] for NPWM and PWM treatments, respectively.

The effect of treatment on Salmonella prevalence is presented by collection in Table 2. No significant treatment differences were observed for any collection period nor were any consistent numerical differences observed. For instance, Salmonella prevalence was higher in calves fed PWM compared with the NPWM treatment for collections 2, 4, and 6, but lower in collections 3 and 7. Salmonella prevalence was relatively consistent in calves fed NPWM, particularly in the first 4 collections, averaging $77.2 \%$ positive over all the collections (range of 59 to $82 \%$ ). Prevalence in the PWM-fed calves ranged from 66 to $87.5 \%$ Salmonella positive in the first 5 collections, the exception being the final collection in which no positive samples were obtained from calves fed PWM. However, only 3 animals were sampled at that time. An effect of collection was observed independent of treatment $(P<0.01)$.

The influence of origin was examined (Table 3) as these calves were born on 4 different dairies before arrival at the location where animals were raised and this study conducted. No fecal samples were obtained on the farm of origin before each animal's arrival; therefore, it is unknown if the calves were infected with Salmonella before arrival, or if they acquired the Salmonella once on the farm. In the first collection, Salmonella 


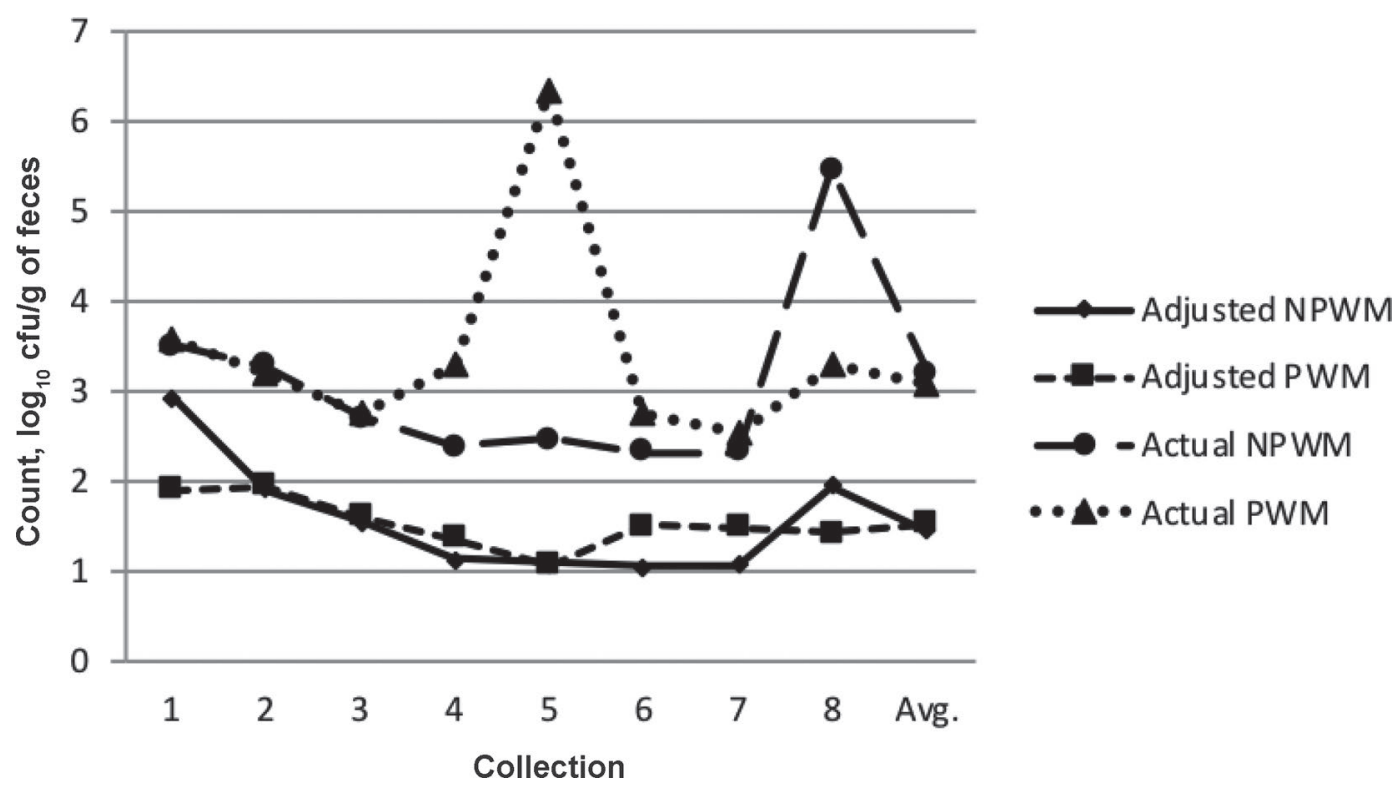

Figure 1. Fecal Salmonella concentrations (actual and adjusted) by collection and averaged across collections in dairy calves fed either pasteurized (PWM) or nonpasteurized waste milk (NPWM). Adjusted concentrations include animals that were culture negative via direct plating but culture positive following enrichment and assigned a concentration of $1.0 \mathrm{cfu}\left(\log _{10}\right) / \mathrm{g}$ of feces.

prevalence in calves from farm $\mathrm{C}$ was similar among treatments, whereas farms $\mathrm{A}, \mathrm{B}$, and $\mathrm{D}$ had more calves in the PWM treatment (particularly farm D) that had Salmonella-positive fecal samples compared with those in the NPWM treatment. However, about twice as many calves were sampled in the PWM treatment as compared with the NPWM in the first collection, which may have influenced these results. Across farms, Salmonella prevalence averaged 78.3 and $87.5 \%$ in the first collection for NPWM and PWM treatments, respectively. Salmonella prevalence at weaning was much lower compared with the previous collections (Table 3) and not influenced by farm of origin. While prevalence was numerically lower in calves fed PWM when examined by farm of origin and across all farms, no statistically significant differences were observed. Across all collections, Salmonella prevalence was higher in the PWM treatment in calves from 3 of the 4 farms

Table 2. Fecal Salmonella prevalence (number and percent positive) by treatment and collection [excluding first and last (weaning) collection] in dairy calves fed either pasteurized or nonpasteurized waste milk

\begin{tabular}{lcccccc}
\hline & \multicolumn{2}{c}{ Nonpasteurized } & & \multicolumn{2}{c}{ Pasteurized } & \\
\cline { 2 - 3 } Collection & No. & $\%$ & & No. & $\%$ & $\begin{array}{c}\text { Total } \\
\text { samples }\end{array}$ \\
\hline 2 & 65 & 78.3 & & 112 & 87.5 & 211 \\
3 & 65 & 78.3 & & 85 & 68 & 208 \\
4 & 62 & 74.7 & & 101 & 82.1 & 206 \\
5 & 58 & 77.3 & & 85 & 75.9 & 187 \\
6 & 36 & 59 & & 41 & 66.1 & 123 \\
7 & 9 & 81.8 & & 0 & 0 & 12 \\
\hline
\end{tabular}

compared with those on the NPWM treatment, but only on farm $\mathrm{D}$ is the difference significant (16 and $52 \%$ Salmonella positive for NPWM and PWM treatments, respectively). Approximately $20 \%$ of the calves from this farm were assigned to the NPWM treatment; therefore, some of the difference in Salmonella prevalence might be explained by the uneven distribution of calves to treatment from this particular farm of origin. Across treatments, Salmonella prevalence was similar among farm origin, averaging $68 \%$ positive (range of 63 to $71 \%)$.

Isolates representing the majority $(737 / 765)$ of $\mathrm{Sal}$ monella-positive fecal samples were serotyped, and the distribution of serotypes is presented in Table 4. Seventeen different serotypes were identified, the majority of which were Salmonella Montevideo (40\%). Anatum was the second most prevalent serotype accounting for $17 \%$ of the isolates, followed by Typhimurium (9.4\%), Kentucky (7.7\%), Altona (4.5\%), Muenchen (3.4\%), and Meleagridis (3.1\%). Salmonella Newport, an important serovar due to its tendency to be multidrug resistant (MDR), accounted for $1.9 \%$ of the isolates. Treatment appeared to influence serotype (Table 5) with a greater $(P<0.05)$ percentage of Typhimurium (87 vs. $13 \%)$, Muenchen ( 88 vs. $12 \%$ ), and Derby (91 vs. $9 \%$ ) recovered from calves fed PWM compared with NPWM-fed calves. Conversely, Newport (12.5 vs. 86\%), Bredeney $(22.2$ vs. $77.8 \%)$, and Muenster (12.5 vs. $87.5 \%)$ were lower $(P<0.05)$ in the PWM treatment. The 2 most prevalent serotypes, Montevideo and Anatum, were not influenced by treatment $(P>0.10)$. 
Table 3. Fecal Salmonella prevalence (number and percent positive) by farm of origin for the first, last (weaning), and across all collections in dairy calves fed either pasteurized or nonpasteurized waste milk

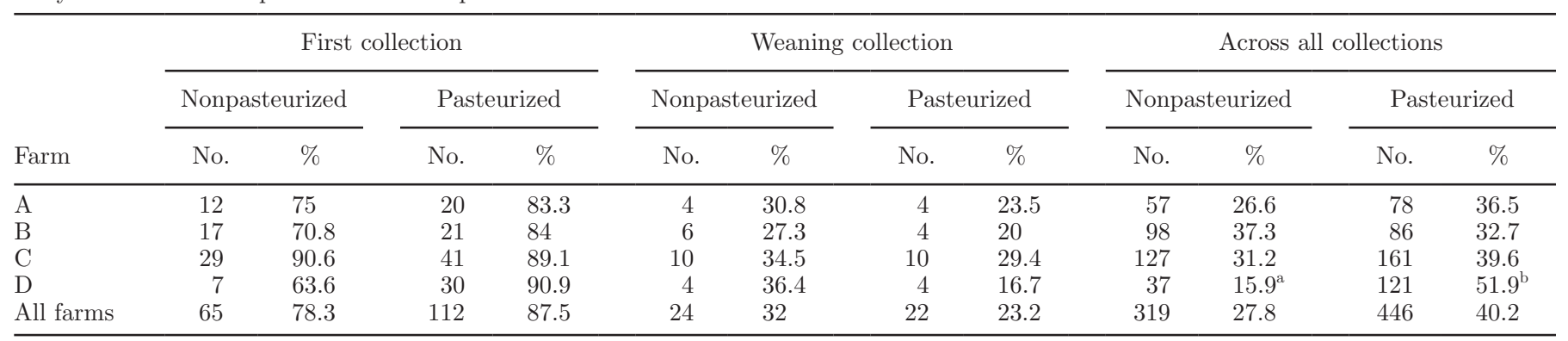

${ }_{\mathrm{a}, \mathrm{b}}$ Percentages of Salmonella within the same collection heading with different superscripts $\operatorname{differ}(P<0.05)$.

Two hundred forty-six isolates from the fourth collection (one isolate per calf if available) were examined for antimicrobial resistance (Table 6). The majority $(66.7 \%)$ were susceptible to all of the antibiotics on the panel, whereas $17.1 \%$ were resistant to only 1 antibiotic. Of the MDR isolates, 1 was resistant to 3 antibiotics, 38 isolates were resistant to 8 or 9 antibiotics, and 1 exhibited resistance to 11 antimicrobials. Isolates resistant to only 1 antibiotic were generally either resistant to sulfisoxazole (11.8\%) or tetracycline (4.5\%). Three isolates (1 each) were resistant to cefoxitin, ceftriaxone, or a combination of tetracycline, nalidixic acid, and chlortetracycline. The MDR-AmpC pattern of resistance [resistance to ampicillin, chloramphenicol, streptomycin, sulfisoxazole, and tetracycline (ACSSuT) plus amoxicillin/clavulanic acid and ceftiofur and a decreased susceptibility to ceftriaxone], or a variation of this pattern, was observed in $15.5 \%$ of the examined isolates. When examined by treatment, the number of pansusceptible isolates was similar among treatments, whereas more isolates resistant to 1 antibiotic were in the NPWM treatment (59.5\%) compared with the

Table 4. Salmonella serotypes recovered from the feces of dairy calves fed either pasteurized or nonpasteurized waste milk ${ }^{1}$

\begin{tabular}{lrr}
\hline Serotype & No. & $\%$ \\
\hline Montevideo & 292 & 39.6 \\
Anatum & 127 & 17.2 \\
Typhimurium & 69 & 9.4 \\
Kentucky & 57 & 7.7 \\
Nontypeable & 49 & 6.6 \\
Altona & 33 & 4.5 \\
Muenchen & 25 & 3.4 \\
Meleagridis & 23 & 3.1 \\
Newport & 14 & 1.9 \\
Cerro & 11 & 1.5 \\
Derby & 11 & 1.5 \\
Bredeney & 9 & 1.2 \\
Muenster & 8 & 1.1 \\
Agona, Cubana, Give, Havana (each) & 2 & 0.3 \\
Brandenberg & 1 & 0.1
\end{tabular}

${ }^{1}$ Fecal samples $(n=1,117)$ collected from 211 calves weekly during the first $4 \mathrm{wk}$ of life.
PWM treatment (40.5). Resistance to sulfisoxazole was similar among treatments, whereas more isolates in the NPWM treatment were resistant to tetracycline (82 vs. $18 \%)$. All of the MDR isolates with the MDR-AmpC pattern of resistance were recovered from calves in the PWM treatment and only one MDR isolate (tetracycline + nalidixic acid + chlortetracycline) was from an animal in the NPWM treatment. The majority of isolates with the MDR-AmpC resistance pattern were identified as Typhimurium (92\%), 2 isolates were Montevideo, and 1 was nontypeable. Farm of origin did not appear to influence MDR-AmpC isolates with 11, 8, 11, and 9 isolates displaying this pattern from farms A, B, $\mathrm{C}$, and D, respectively (data not shown).

Waste milk samples were collected on 6 occasions during the experiment, before each fecal collection, and cultured for Salmonella, generic E. coli, and fecal coliforms (data not shown). Of the 12 waste milk samples, only 1 nonpasteurized sample was culture positive for Salmonella. Two Salmonella isolates were examined and found to be susceptible to all antibiotics on the

Table 5. Effect of treatment on Salmonella serotypes recovered from the feces of dairy calves fed either pasteurized or nonpasteurized waste milk $^{1}$

\begin{tabular}{|c|c|c|c|c|c|}
\hline \multirow[b]{2}{*}{ Serotype } & \multicolumn{2}{|c|}{ Nonpasteurized } & \multicolumn{2}{|c|}{ Pasteurized } & \multirow[b]{2}{*}{$P$-value } \\
\hline & No. & $\%$ & No. & $\%$ & \\
\hline Montevideo & 114 & 39 & 178 & 61 & 0.29 \\
\hline Anatum & 62 & 48.8 & 65 & 51.2 & 0.11 \\
\hline Typhimurium & 9 & 13 & 60 & 87 & $<0.0001$ \\
\hline Kentucky & 34 & 59.6 & 23 & 40.4 & 0.06 \\
\hline Altona & 17 & 51.5 & 16 & 48.5 & 0.27 \\
\hline Muenchen & 3 & 12 & 22 & 88 & 0.007 \\
\hline Meleagridis & 11 & 47.8 & 12 & 52.2 & 0.58 \\
\hline Newport & 12 & 85.7 & 2 & 12.5 & 0.005 \\
\hline Cerro & 4 & 36.4 & 7 & 63.6 & 0.66 \\
\hline Derby & 1 & 9.1 & 10 & 90.9 & 0.05 \\
\hline Bredeny & 7 & 77.8 & 2 & 22.2 & 0.05 \\
\hline Muenster & 7 & 87.5 & 1 & 12.5 & 0.04 \\
\hline
\end{tabular}

${ }^{1}$ Fecal samples $(\mathrm{n}=1,117)$ collected from 211 calves weekly during the first 4 wk of life. Nontypeable Salmonella: 21 and 28 isolates in nonpasteurized and pasteurized treatments, respectively. 
panel. They were not serotyped. Generic E. coli and fecal coliforms were cultured from all 6 of the NPWM samples and all PWM samples were negative. Of the 14 $E$. coli isolates examined for antimicrobial resistance, 6 were pansusceptible, 5 were resistant to 1 antibiotic (sulfisoxazole), 1 was resistant to 2 antibiotics (streptomycin and tetracycline), and 2 were resistant to 6 antibiotics (ACSSuT pattern of resistance). Fifteen fecal coliform isolates were examined and all were resistant to at least 1 antimicrobial. Eight isolates were resistant to sulfisoxazole or ampicillin, 3 isolates were resistant to 2 or 3 antibiotics, and 4 isolates were resistant to 6 or 7 (ACSSuT) antibiotics.

\section{DISCUSSION}

In the current study, reluctance by the dairy to feed nonpasteurized waste milk is the reason for the unbalanced number of calves in the 2 treatments. Whether previous experience with nonpasteurized waste milk or the fear of changing from pasteurized to nonpasteurized waste milk is behind this decision is unknown. However, the concerns appear well founded. The prevalence of Salmonella in raw milk and colostrum has been reported previously (Sweeney et al., 1992; Butler et al., 2000; Houser et al., 2008), and significant reductions in total bacterial counts (Ruzante et al., 2008) as well as specific pathogens such as Salmonella, Mycoplasma, and M. paratuberculosis (Stabel et al., 2004) have been reported in waste milk following pasteurization. Therefore, pasteurization of waste milk would seem a logical procedure to ensure calf health and reduce pathogen exposure. Results of this study, however, are somewhat surprising, in that pasteurization of waste milk did not have any appreciable effect on fecal Salmonella concentrations or prevalence compared with those fed NPWM. Beyond the lack of treatment differences in fecal Salmonella, morbidity, mortality, overall health, and calf performance were all reported to be similar among treatments by the dairy farmer.

Recolonization and recontamination of waste milk occurs rapidly following pasteurization (Ruzante et al., 2008) and may account for, at least in part, the lack of differences in the 2 treatments in this study. Therefore, although pathogenic bacteria in the waste milk can be eliminated, without proper and consistent postpasteurization milk handling procedures, the total bacterial load reaching the calves may not be different when comparing pasteurized to nonpasteurized waste milk. As has been reported previously by these authors and others (Fitzgerald et al., 2003; Edrington et al., 2004; Loneragan et al., 2012), dairy cattle in this region of the United States are frequently infected with Salmonella, as is the environment in which they are housed. Therefore, recontamination of the pasteurized waste milk with Salmonella before calf feeding is a possible transmission vector; however, as reported above, the PWM samples were culture negative and only nonpasteurized samples yielded viable fecal coliforms, generic E. coli, and Salmonella. Therefore, Salmonella in the dairy environment is a more plausible vector of transmission of Salmonella than feeding contaminated waste milk in this group of calves. Granted, contamination of the waste milk was possible postpasteurization and our sampling protocol may have missed contamination occurring later in the feeding process. All cattle on the dairy farm, not just calves, have been reported to shed Salmonella in their feces (Edrington et al., 2008b); hence, the close proximity of these calves to one another, as well as to other cattle on the farm, likely results

Table 6. Antimicrobial resistance in Salmonella isolates recovered from the feces of dairy calves fed either pasteurized or nonpasteurized waste milk ${ }^{1}$

\begin{tabular}{|c|c|c|c|c|c|c|}
\hline \multirow[b]{2}{*}{ Resistant to: } & \multicolumn{2}{|c|}{ Nonpasteurized } & \multicolumn{2}{|c|}{ Pasteurized } & \multicolumn{2}{|c|}{ Across treatment } \\
\hline & No. & $\%$ & No. & $\%$ & No. & $\%$ \\
\hline No resistance & 77 & 46.9 & 87 & 53.1 & 164 & 66.7 \\
\hline 1 antibiotic & 25 & 59.5 & 17 & 40.5 & 42 & 17.1 \\
\hline 3 antibiotics & 1 & 100 & 0 & 0 & 1 & 0.004 \\
\hline 8 to 11 antibiotics & 0 & 0 & 39 & 100 & 39 & 15.9 \\
\hline Tetracycline & 9 & 81.8 & 2 & 18.2 & 11 & 4.5 \\
\hline Sulfisoxazole & 15 & 51.7 & 14 & 48.3 & 29 & 11.8 \\
\hline Cefoxitin & 0 & 0 & 1 & 100 & 1 & 0.004 \\
\hline Ceftriaxone & 1 & 100 & 0 & 0 & 1 & 0.004 \\
\hline Tet $+\mathrm{Nal}+\mathrm{Chlor}^{2}$ & 1 & 100 & 0 & 0 & 1 & 0.004 \\
\hline MDR AmpC pattern ${ }^{3}$ & 0 & 0 & 39 & 100 & 39 & 15.9 \\
\hline
\end{tabular}

${ }^{1}$ Fecal samples $(\mathrm{n}=1,117)$ collected from 211 calves weekly during the first 4 wk of life.

${ }^{2}$ Tetracycline, nalidixic acid, and chlortetracycline.

${ }^{3} \mathrm{MDR}$ AmpC pattern of resistance = resistance to ampicillin, chloramphenicol, streptomycin, sulfisoxazole, and tetracycline plus amoxicillin/clavulanic acid and ceftiofur and a decreased susceptibility to ceftriaxone. 
in significant Salmonella exposure. That, coupled with an undeveloped, immature gastrointestinal system of neonatal calves, may provide opportunities for rapid Salmonella dissemination.

More recently it was reported that dairy calves are born with Salmonella already present within the GIT and lymphatic system (Hanson et al., 2016). Therefore, with Salmonella already infecting the animals, either acquired in utero or in the first few days of life, pasteurization of waste milk would likely have little to no effect on fecal Salmonella prevalence as observed in this study. This may also explain the differences in prevalence observed due to farm of origin in the current study. Fecal Salmonella prevalence in this region of the United States has been shown to vary among farms within a small geographical area (Edrington et al., 2004; Loneragan et al., 2012); therefore, it is reasonable to assume that the percentage of calves born infected with Salmonella will vary by farm as well. Because collecting fecal samples at birth before transport to the study farm was not possible, we can only speculate as to the timeframe and method by which these calves were infected with Salmonella.

Treatment did affect the prevalence of serotype recovered but not consistently. In some cases, feeding PWM resulted in more Typhimurium, Muenchen, and Derby, whereas more Newport, Bredeney, and Muenster were isolated from calves fed NPWM. The reasons for these differences are unknown. Only Newport was influenced by farm of origin, but as calves from all 4 farms of origin were represented in each treatment, this should not have influenced the treatment effect observed.

Previous research conducted by the authors evaluated the effect of pasteurizing waste milk before feeding on bacterial diversity of the intestinal flora in dairy calves (Edrington et al., 2012). The total number of different characterized and noncharacterized bacterial species was greater for calves fed pasteurized waste milk, which is surprising as it is expected that the pasteurization process would provide a "cleaner" product in terms of bacteria present and therefore less species diversity within the GIT. This was observed in calves 1 wk old but not in older calves. The authors hypothesized that the increased diversity in the older calves was likely a result of recolonization of the waste milk following pasteurization as has been reported previously (Edrington et al., 2012). Similar to these results, Salmonella populations were not different among calves fed PWM or NPWM, indicating that milk-borne Salmonella is not an important vector for transmission to young dairy calves, at least not on the farm enrolled in this study.

Of interest, albeit difficult to explain, is the observation in which all resistant isolates with the MDR-AmpC resistance pattern, or a variation of this pattern, were from calves in the PWM treatment. The majority of these isolates were the serotype Typhimurium, which as mentioned above, were more frequently recovered from calves in the PWM treatment. Perhaps, the gut microbiome is altered in such a way by the feeding of PWM as to provide Salmonella Typhimurium, which is often MDR, a competitive advantage. Possibly feeding NPWM introduces more commensal bacteria that colonize the GIT and out-competes or inhibits Typhimurium compared with other serotypes. In previous research we observed that of all the animals on a dairy farm, the most likely to harbor MDR Salmonella were the young, preweaned calves and cows in the hospital pen (Edrington et al., 2008a). We speculated that a possible explanation may lie in the state of the GIT of these 2 groups of animals. Mature cows in the hospital pen are generally not eating, or eating very little, both scenarios that significantly disrupt the normal gut balance and microflora. Young calves are in the process of developing a normal gut microflora and transitioning from a liquid to solid diet. In both situations, the disruption (sick cows) or development (young calves) of the microflora may allow for certain serotypes such as Typhimurium to predominate the Salmonella serotypes within the gut, whereas in a healthy animal the predominant Salmonella are more frequently pansusceptible serotypes such as Montevideo and Anatum. As resistance generally comes at a physiological expense to the bacteria, it may be that the MDR strains are only strong enough to survive in a compromised gut. There were no indications that animals in either treatment were influenced negatively by treatment, or otherwise not in good health.

\section{CONCLUSIONS}

Overall, the results of the current research are somewhat surprising because no noteworthy differences were observed in fecal Salmonella concentrations or prevalence among calves fed PWM or NPWM. Of interest, albeit difficult to interpret, was the clustering of MDR Salmonella Typhimurium in the PWM treatment. In this commercial dairy setting, it would appear from these data that milk-borne Salmonella is not an important vector for transmission to young dairy calves, at least not on this particular farm. Even so, extrapolation of this data to other farms should be done with caution and the potential benefits of pasteurization in disease prevention clearly outweigh the potential risks of feeding a nonpasteurized product and warrant incorporation into any calf-rearing program using nonsaleable waste milk for feeding young dairy neonates. 


\section{ACKNOWLEDGMENTS}

This project was funded in part, by beef and veal producers and importers through their \$1-per-head checkoff and was produced for the Cattlemen's Beef Board (Denver, $\mathrm{CO}$ ) and state beef councils by the National Cattlemen's Beef Association (Denver, CO). Mention of trade name, proprietary product, or specific equipment does not constitute a guarantee or warranty by the USDA and does not imply its approval to the exclusion of other products that may be suitable.

\section{REFERENCES}

Andrews, W. H., and T. Hammack. 2008. Salmonella. Chapter 5 in Bacteriological Analytical Manual, US Food and Drug Administration, Silver Spring, MD.

Butler, J. A., S. A. Sickles, C. P. Johanns, and R. F. Rosenbusch. 2000 Pasteurization of discard mycoplasma milk used to feed calves: Thermal effects on various mycoplasma. J. Dairy Sci. 83:22852288

Chardavoyne, J. R., J. A. Ibeawuchi, E. M. Kesler, and K. M. Borland. 1979. Waste milk from antibiotic treated cows as feed for young calves. J. Dairy Sci. 62:1285-1289.

CLSI (Clinical and Laboratory Standards Institute). 2010. Performance Standards for Antimicrobial Susceptibility Testing; Twentieth Informational Supplement. CLSI document M100-S20. Clinical and Laboratory Standards Institute, Wayne, PA.

Edrington, T. S., T. R. Callaway, R. C. Anderson, and D. J. Nisbet. 2008a. Prevalence of multidrug-resistant Salmonella on commercial dairies utilizing a single heifer raising facility. J. Food Prot. $71: 27-34$.

Edrington, T. S., S. E. Dowd, R. F. Farrow, G. R. Hagevoort, T. R Callaway, R. C. Anderson, and D. J. Nisbet. 2012. Development of colonic microflora as assessed by pyrosequencing in dairy calves fed waste milk. J. Dairy Sci. 95:4519-4525.

Edrington, T. S., M. E. Hume, M. L. Looper, C. L. Schultz, A. C. Fitzgerald, T. R. Callaway, K. J. Genovese, K. M. Bischoff, J. L. McReynolds, R. C. Anderson, and D. J. Nisbet. 2004. Variation in the faecal shedding of Salmonella and E. coli O157:H7 in lactating dairy cattle and examination of Salmonella genotypes using pulsed-field gel electrophoresis. Lett. Appl. Microbiol. 38:366-372.

Edrington, T. S., T. T. Ross, T. R. Callaway, C. H. Martinez, M. E Hume, K. J. Genovese, T. L. Poole, R. C. Anderson, and D. J. Nisbet. 2008b. Investigation into the seasonal salmonellosis in lactating dairy cattle. Epidemiol. Infect. 136:381-390.

Elizondo-Salazar, J. A., C. M. Jones, and A. J. Heinrichs. 2010. Evaluation of calf milk pasteurization systems on 6 Pennsylvania dairy farms. J. Dairy Sci. 93:5509-5513.

Fitzgerald, A. C., T. S. Edrington, M. L. Looper, T. R. Callaway, K. J. Genovese, K. M. Bischoff, J. L. McReynolds, J. D. Thomas, R. C. Anderson, and D. J. Nisbet. 2003. Antimicrobial susceptibility and factors affecting the shedding of E. coli O157:H7 and Salmonella in dairy cattle. Lett. Appl. Microbiol. 37:392-398.

FDA (Food and Drug Administration). 2011. National Antimicrobial Resistance Monitoring System-Enteric Bacteria (NARMS): 2009
Executive Report. US Department of Health and Human Services, Food and Drug Administration, Rockville, MD.

Hanson, D. L., G. H. Loneragan, T. R. Brown, D. J. Nisbet, M. E. Hume, and T. S. Edrington. 2016. Evidence supporting vertical transmission of Salmonella in dairy cattle. Epidemiol. Infect. 144:962-967.

Houser, B. A., S. C. Donaldson, S. I. Kehoe, A. J. Heinrichs, and B. M. Jayarao. 2008. A survey of bacteriological quality and the occurrence of Salmonella in raw bovine colostrums. Foodborne Pathog. Dis. 5:853-858

Jamaluddin, A. A., T. E. Carpenter, D. W. Hird, and M. C. Thurmond. 1996. Economics of feeding pasteurized colostrums and pasteurized waste milk to dairy calves. J. Am. Vet. Med. Assoc. 209:751-756.

Kesler, E. M. 1981. Feeding mastitic milk to calves: A review. J. Dairy Sci. 64:719-723

Keys, J. E., R. E. Pearson, and B. T. Weinland. 1980. Performance of calves fed fermented mastitic milk, colostrums, and fresh whole milk. J. Dairy Sci. 63:1123-1127.

Loneragan, G. H., D. U. Thomson, R. M. McCarthy, H. E. Webb, A. E. Daniels, T. S. Edrington, D. J. Nisbet, S. J. Trojan, S. C. Rankin, and M. M. Brashears. 2012. Salmonella diversity and burden in cows on and culled from dairy farms in the Texas high plains. Foodborne Pathog. Dis. 9:549-555.

Moore, G. R., H. Rothenbacher, M. V. Bennett, and R. D. Barner 1962. Bovine salmonellosis. J. Am. Vet. Med. Assoc. 141:841-844.

Rings, D. M. 1985. Salmonellosis in calves. Vet. Clin. North Am. Food Anim. Pract. 1:529-539.

Ruzante, J. M., I. A. Gardner, J. S. Cullor, W. L. Smith, J. H. Kirk, and J. M. Adaska. 2008. Isolation of Mycobacterium avium ssp. paratuberculosis from waste milk delivered to California calf ranches. Foodborne Pathog. Dis. 5:681-686.

Salisbury, J. G., T. J. Nicholls, A. M. Lammerding, J. Turnidge, and M. J. Nunn. 2002. A risk analysis framework for the long-term management of antibiotic resistance in food-producing animals. Int. J. Antimicrob. Agents 20:153-164.

Selim, S. A., and J. S. Cullor. 1997. Number of viable bacteria and presumptive antibiotic residues in milk fed to calves on commercial dairies. J. Am. Vet. Med. Assoc. 211:1029-1035.

Stabel, J. R., S. Hurd, L. Calvente, and R. F. Rosenbusch. 2004. Destruction of Mycobacterium paratuberculosis, Salmonella spp., and Mycoplasma spp. in raw milk by a commercial on-farm high-temperature, short-time pasteurizer. J. Dairy Sci. 87:2177-2183.

Sundlof, S. F., J. B. Kaneene, and R. A. Miller. 1995. National survey of veterinarian-initiated drug use in lactating dairy cows. J. Am. Vet. Med. Assoc. 207:347-352.

Sweeney, R. W., R. H. Whitlock, and A. E. Rosenberger. 1992. Mycobacterium paratuberculosis cultured from milk and supramammary lymph nodes of infected asymptomatic cows. J. Clin. Microbiol. 30:166-171.

USDA National Agricultural Statistics Service. 2002. Milk Cows and Production. Accessed Dec. 2002. https://www.aphis.usda .gov/aphis/ourfocus/animalhealth/monitoring-and-surveillance/ nahms/nahms dairy studies/.

Wray, C., S. Furniss, and C. L. Benham. 1990. Feeding antibioticcontaminated wastemilk to calves-effects on physical performance and antibiotic sensitivity of gut flora. Br. Vet. J. 146:80-87. 